\title{
INTERANNUAL VARIATIONS AND DISTRIBUTION OF HUMUS COMPONENTS IN SALINE-ALKALI PADDY SOILS
}

\author{
LIU, Q. ${ }^{1,2}-$ TANG, J. ${ }^{1 *}-$ WANG, J. ${ }^{1}-$ QU, Y. ${ }^{1}$ \\ ${ }^{1}$ College of Environment and Resources, Jilin University, Changchun 130012, China \\ ${ }^{2}$ College of Landscape Architecture, Changchun University, Changchun 130012, China \\ (phone: +86-181-0431-1389) \\ ${ }^{*}$ Corresponding author \\ e-mail: hamiqi.365@163.com; phone: +86-181-0431-1389
}

(Received 24 $4^{\text {th }}$ Oct 2019; accepted $2^{\text {nd }}$ Jul 2020)

\begin{abstract}
This study analyzed saline-alkali paddy sois of different reclamation durations in the western Jilin Province of China to identify the distribution and variation of humus components so as to provide a scientific basis for rationally utilizing land resources. Test samples were collected from the former Guoerluosi irrigation area in western Jilin. Paddies with five different farming durations (1, 10, 20, 30 and 55 years) under which single-cropping rice was planted from May to October every year and where all other conditions were common, were selected as the test plots. The results showed that: (1) The ratio of Soil Humus content to organic carbon in paddy field with different cultivation years showed humin > humus carbon > humic acid > fulvic acid, and the content of Humus and its components decreased gradually with the deepening of soil layer; (2) Soil humus components were closely correlated with the content of organic carbon in soil as the regeneration and activation of soil humus had a direct bearing on the variations of the organic carbon pool in soil; (3) The HA/FA and PQ values of saline-alkali paddy soil were positively correlated with farming duration, with the biggest increase in the $20-30 \mathrm{~cm}$ soil layer.
\end{abstract}

Keywords: cultivation, carbon variation, vertical distribution, saline-alkaline rice fields, humus composition

\section{Introduction}

[Study significance] A large amount of $\mathrm{CO}_{2}$ has accumulated in the Earth's atmosphere since the 19th century due to the conversion of natural forests and grasslands to farmland (Jonczak, 2014). Therefore, the ebb and flow of carbon in farmland soils will exert direct influences on the atmospheric $\mathrm{CO}_{2}$ level (Shao et al., 2018). The former Guoerluosi (Qianguo) irrigation area, western Jilin Province, China, is one of the four largest irrigation areas in Northeast China and also one of the world's three largest areas of saline-alkali soil; therefore, the region is of importance for global carbon cycle studies (Tang et al., 2011). Included among recent efforts to improve land salinization in this area are the artificial enclosures of degraded grasslands and some dry land or the conversion of these areas to paddy fields. Changing carbon fixation capacity, soil fertility and $\mathrm{CO}_{2}$ emissions of paddy soils is evident with changing land use (Ding et al., 2013; Zhang et al., 2015). Therefore, it is of great significance to study the factors driving the variations and regeneration patterns of humus components in saline-alkali soils under different farming durations so as to derive knowledge for improving the soil quality, fertility and carbon sequestration capacity of saline-alkali paddy fields. [Previous study progress] Soil humus is one of the main components of soil organic matter and is a key indicator of soil fertility and quality as its amount and composition can reflect certain soil-forming conditions and processes (Six et al., 2004; Dong et al., 2017; Wiao et al., 2020). As an organic substance formed by the decomposition of dead 
organisms by soil microorganisms, humus is mostly derived from plant litter and decaying roots. Humus is not a single organic compound, but rather a mixture of organic compounds with commonalities and differences in composition, structure and properties, including humus carbon (HE), humic acid (HA), fulvic acid (FA) and humin (HM) (Brady, 1974; Bunting, 1987; Brady et al., 2000; Zheng, 2019). Much research, both in China and globally, has been performed in recent years on the factors influencing the composition of soil humus (Andreetta et al., 2011; Vos et al., 2015; Dong and Dou, 2017; Daryanti et al., 2019). It has generally been shown that humus is a relatively stable soil component and is notably affected by the geographical environment and biological factors (Zhu et al., 2018). [Study approach] It is known that farming practices and duration both affect the content and distribution of soil humus to some extent (Wang et al., 2015; Li et al., 2016). Therefore, the present study has analyzed the variation in the vertical distribution of humus over time in saline-alkali paddy soil. [Proposed solutions to key problems] The present study has analyzed the variations in the composition of humus for different paddy soil layers as a result of farming duration to provide a scientific basis for the rational use of land resources so as to improve both rice yield and soil carbon sequestration capacity. Saline-alkali soil is an important reserve land resource. Through this study, the response of Humus composition to reclamation years and soil layers can be determined, which is the focus of this study, the results can provide reference for the rational development and utilization of saline-alkali land.

\section{Materials and Methods}

\section{Study Area}

The study area is located in the irrigation region of the former Guoerluosi Mongolian Autonomous County of Jilin Province (E123 ${ }^{\circ} 35^{\prime}-125^{\circ} 18^{\prime}$, N44 $17^{\prime}-45^{\circ} 28^{\prime}$ ). This region has a temperate continental monsoon climate with four distinct seasons. Highest and lowest temperatures are approximately $36^{\circ} \mathrm{C}$ and $-36^{\circ} \mathrm{C}$, respectively. The region is dry and windy in spring, hot and humid in summer, cool in autumn with a large diurnal temperature difference and cold in winter with little snowfall and a long freezing period. The annual averages of sunny days, hours of sunshine and temperature are $110 \mathrm{~d}, 2,879$ $\mathrm{h}$ and $4.5^{\circ} \mathrm{C}$, respectively. The first day of frost generally falls in the middle of or late September, whereas the final frost date generally falls between late April and early May; hence, the frost-free duration is $130-140 \mathrm{~d}$. The average annual precipitation is $400-500 \mathrm{~mm}$. The annual average evaporation is $>1,200 \mathrm{~mm}$, with evaporation from April to May accounting for $531.2 \mathrm{~mm}$ or $45.2 \%$ of the annual total (Tang et al., 2012; Liu et al., 2018). Single-cropping rice seedlings are generally planted in mid-May, and the mature plants are harvested in October. The rice growth stage is mainly supported by application of urea and potassium and phosphate fertilizers. Figure 1 shows the monthly average precipitation and temperature in the study area in 2015.

\section{Test Design}

Investigation of maps of soil types and land use types combined with the paddy field farming history and field investigation was performed to facilitate the selection of representative sampling plots and universal test results (Fig. 2). Sampling was conducted on plots with paddy soils farmed over five different durations $(1,10,20,30$ 
and 55 years) under basically the same natural conditions. Three $20 \mathrm{~m} \times 20 \mathrm{~m}$ sampling areas were established in each sampling plot before rice planting in 2015 (early May). Each sampling area contained five S-shaped sampling points where soils were collected from five levels $(0 \mathrm{~cm}-10 \mathrm{~cm}, 10 \mathrm{~cm}-20 \mathrm{~cm}, 20 \mathrm{~cm}-30 \mathrm{~cm}, 30 \mathrm{~cm}-40 \mathrm{~cm}$ and $40 \mathrm{~cm}-$ $50 \mathrm{~cm}$ ), soil samples were taken by a drill with a diameter of $10 \mathrm{~cm}$. The collected soil samples were then processed to remove grit and plant residues, air-dried and then sequentially filtered with $0.2 \mathrm{~mm}$ and $0.125 \mathrm{~mm}$ sieves before being analyzed for soil organic carbon and humus components (Fig. 3). The basic information of the plots is shown in Table 1.

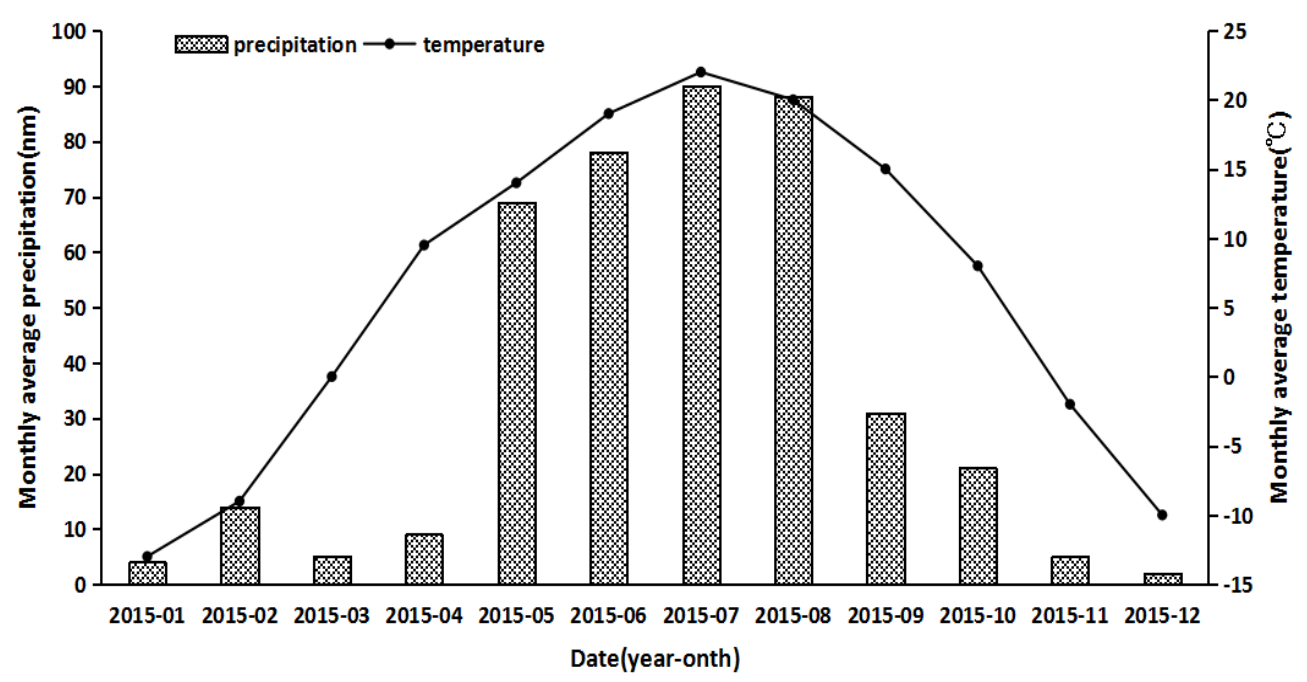

Figure 1. Mean precipitati on and temperature in the study area in 2015

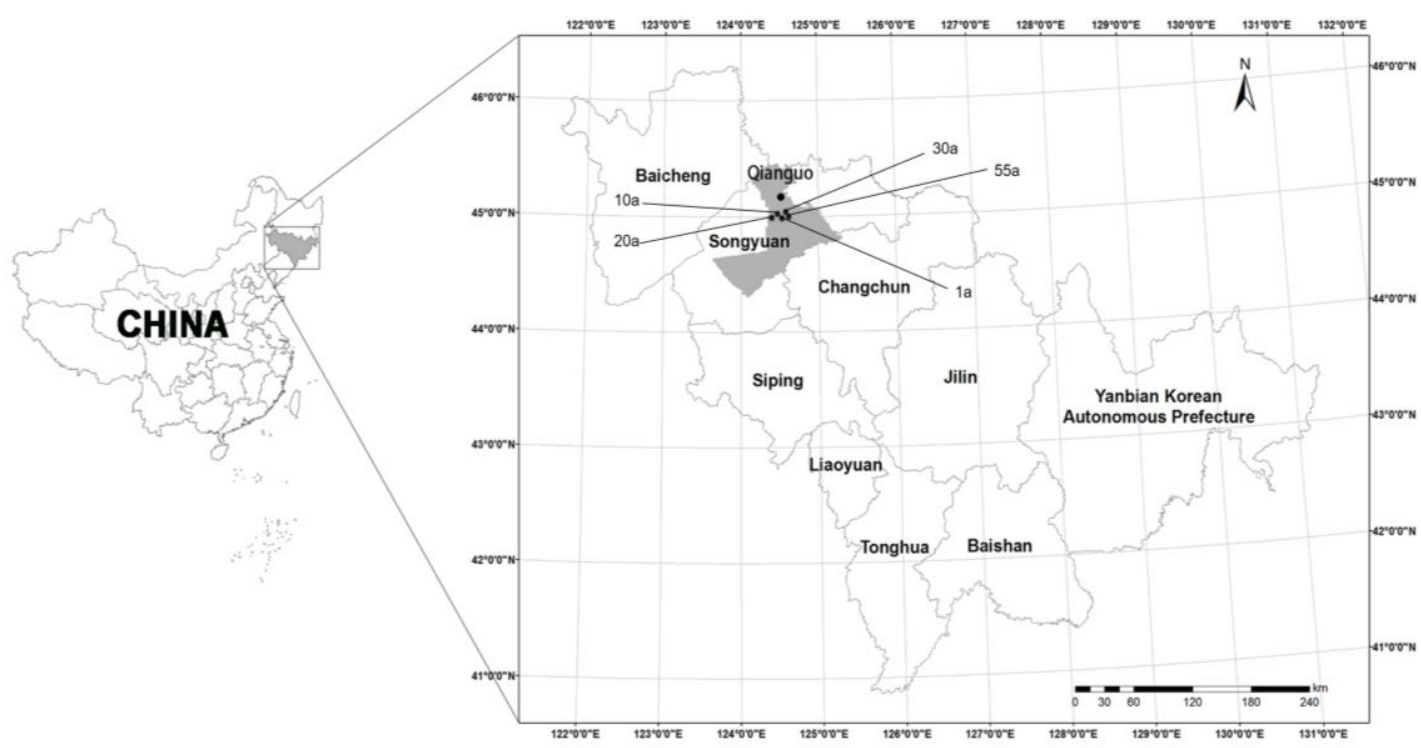

Figure 2. The location of the study area and the distribution of the sampling points 


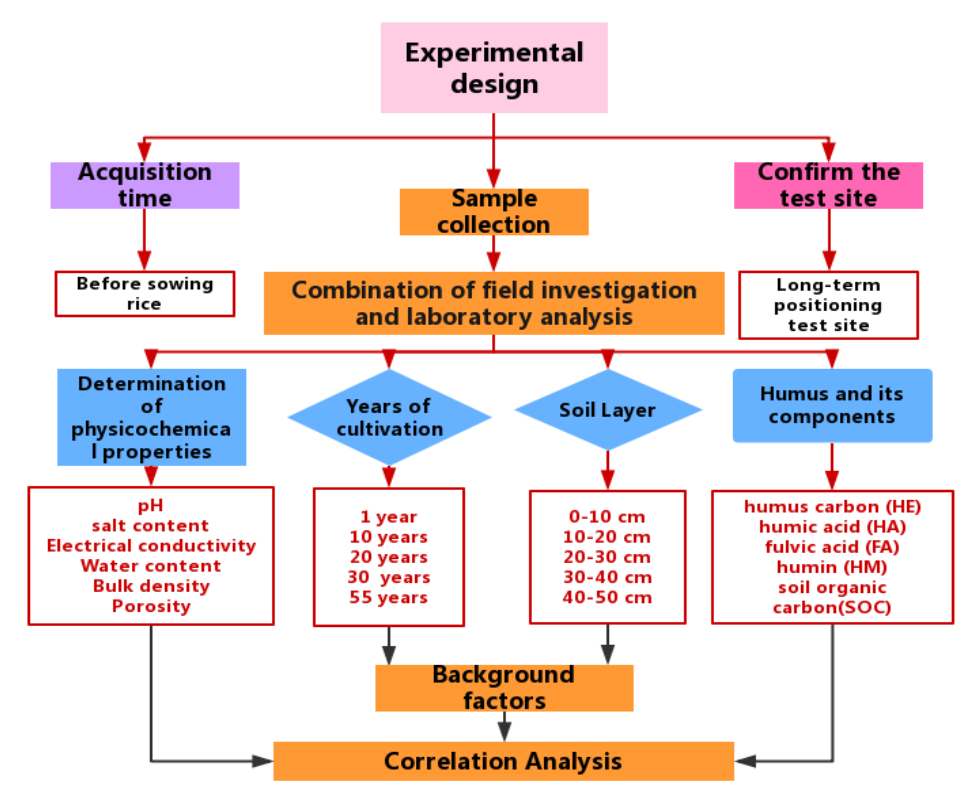

Figure 3. Test Design and procedure

Table 1. Overview of study area

\begin{tabular}{|c|c|c|c|c|c|c|c|c|c|}
\hline $\begin{array}{l}\text { Sample } \\
\text { number }\end{array}$ & $\begin{array}{l}\text { Cultivation } \\
\text { history }\end{array}$ & $\begin{array}{l}\text { Geographical } \\
\text { location }\end{array}$ & $\begin{array}{l}\text { Soil } \\
\text { type }\end{array}$ & pH & $\begin{array}{c}\begin{array}{c}\text { Salt } \\
\text { content }\end{array} \\
1 \%\end{array}$ & $\begin{array}{c}\text { Electrical } \\
\text { conductivity } \\
/ \mathbf{m s} \cdot \mathbf{c m}^{-1}\end{array}$ & $\begin{array}{c}\begin{array}{c}\text { Water } \\
\text { content }\end{array} \\
1 \%\end{array}$ & $\begin{array}{c}\text { Bulk } \\
\text { density } \\
/ \mathrm{g} \cdot \mathrm{cm}^{-3}\end{array}$ & $\begin{array}{c}\text { Porosity } \\
1 \%\end{array}$ \\
\hline R1 & $1 \mathrm{a}$ & 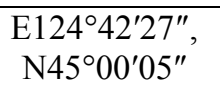 & $\begin{array}{l}\text { rice } \\
\text { soil }\end{array}$ & 8.7 & 2.088 & 0.306 & 0.54 & 1.01 & 0.63 \\
\hline R10 & $10 \mathrm{a}$ & $\begin{array}{l}\mathrm{E} 124^{\circ} 41^{\prime} 40^{\prime \prime} \\
\mathrm{N} 45^{\circ} 00^{\prime} 23^{\prime \prime}\end{array}$ & $\begin{array}{l}\text { rice } \\
\text { soil }\end{array}$ & 8.53 & 1.923 & 0.218 & 0.48 & 0.87 & 0.67 \\
\hline R20 & $20 \mathrm{a}$ & 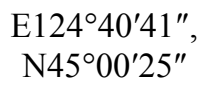 & $\begin{array}{l}\text { rice } \\
\text { soil }\end{array}$ & 8.56 & 1.961 & 0.211 & 0.50 & 0.83 & 0.70 \\
\hline R30 & $30 \mathrm{a}$ & 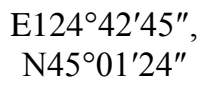 & $\begin{array}{l}\text { rice } \\
\text { soil }\end{array}$ & 8.12 & 1.784 & 0.132 & 0.47 & 0.90 & 0.66 \\
\hline R55 & $55 \mathrm{a}$ & $\begin{array}{l}\mathrm{E} 124^{\circ} 43^{\prime} 03^{\prime \prime} \\
\mathrm{N} 45^{\circ} 00^{\prime} 19^{\prime \prime}\end{array}$ & $\begin{array}{l}\text { rice } \\
\text { soil }\end{array}$ & 8.07 & 1.736 & 0.104 & 0.48 & 0.92 & 0.64 \\
\hline
\end{tabular}

\section{Test Indicators and Methods}

Soil organic carbon and humus components were determined using the potassium dichromate volumetry-thermodilution method (Cha, 2017). The humus components were extracted by weighing 2.5 gair-dried soil sample in $100 \mathrm{~mL}$ centrifuge tube, adding $0.1 \mathrm{~mol} \cdot \mathrm{L}^{-1} \quad \mathrm{Na}_{4} \mathrm{P}_{2} \mathrm{O}_{7} \cdot 10 \mathrm{H}_{2} \mathrm{O}, 0.1 \mathrm{~mol} \cdot \mathrm{L}^{-1} \mathrm{NaOH}$ mixture $50 \mathrm{~mL}$, shaking $145 \mathrm{r} \cdot \mathrm{min}^{-1}$ at $70{ }^{\circ} \mathrm{C}$ in a constant temperature water bath oscillator, extracting for $1 \mathrm{~h}$, then centrifuging and filtering, the humic acid (HE) can be extracted in a $50 \mathrm{~mL}$ volumetric flask. The residue in the centrifuge tube is called crude humin (HM). The Alkali extract was extracted with $30 \mathrm{~mL}$ in $50 \mathrm{~mL}$ flask, and $1 \mathrm{~mol} \cdot \mathrm{L}^{-1} \mathrm{H} 2 \mathrm{SO} 4$ was added to adjust the $\mathrm{pH}$ value to $1.0-1.5$. Place the solution in a $60-70{ }^{\circ} \mathrm{C}$ water bath for 1-2 $\mathrm{h}$, then leave overnight. On the next day, the solution was quantitatively filtered 
with medium speed filter paper, and the precipitate was HA, and the solution was FA (Zhang et al., 2004).

\section{Data Processing}

Statistical analysis was performed using SPSS 19.0 statistical software (SPSS Inc., Chicago, IL, USA). Statistical significance of soil organic carbon and humus components in different reclamation years and in different soil layers was determined by one-way analysis of variance (ANOVA) and Fisher's least significant difference (LSD) test. Multivariate analysis of variance was used to examine the differences of soil carbon and Statistical significance of soil organic carbon and humus in different reclamation years and soil layers. Pearson correlation analysis was used to estimate the relationship between organic carbon and humus components.

\section{Results}

\section{Interannual Variation in Saline-alkali Paddy Soil Humus Components}

\section{Variations in Humus Carbon Content}

The content of extractable humus carbon (HE) in reclaimed soil increased significantly, and showed an increasing trend with the extension of reclamation years. He in reclaimed soil was about $5.64-8.22 \mathrm{~g} \cdot \mathrm{kg}^{-1}$ in 55 years, which was about 10 times higher than that in unreclaimed soil. He was significantly higher in $0-10 \mathrm{~cm}$ than in $40-50 \mathrm{~cm}(P<0.05)$ in different soil layers, and there was no significant difference in HE between $30-40 \mathrm{~cm}$ and $40-50 \mathrm{~cm}$ soil layers (Fig. 4).

\section{Variations in Humic Acid Content}

Humic acid (HA) is a brown to deep-brown extractable humus that is soluble in dilute alkali soil but dilute acid soil. HA has colloidal properties and is one of the relatively active parts of soil humus, playing an important role in soil structure composition (Gong et al., 2009; Chu et al., 2013). As illustrated by Figure 5, the HA content of each soil layer generally increased with increasing farming duration, with the lowest and highest HA contents were found in R1 and R55 soils, respectively. The HA content of the R0 $0 \mathrm{~cm}-10 \mathrm{~cm}$ soil layer was significantly higher than those of the R1, R10, R20 and R30 soils by $48.25 \%, 29.01 \%, 17.35 \%$ and $11.19 \%$, respectively $(P<0.05)$. For the $10 \mathrm{~cm}-20 \mathrm{~cm}$ soil layer, no significant difference in HA content were evident between R1, R10 and R20 soils as well as between R30 and R55 soils; however R55 HA content increased by $50 \%$ compared with R1. For the $20 \mathrm{~cm}-30 \mathrm{~cm}$ soil layer, no significant difference in HA content was evident between R10, R20 and R30 soils; however, R55 HA content was significantly higher than those of other farming durations, and increased by $68.87 \%$ compared with R1. For the $30 \mathrm{~cm}-40 \mathrm{~cm}$ soil layer, R20 soil HA content was significantly higher than those of R1, R10 and R30 soils; the R55 soil HA content was in particular higher than those of other farming years. For the $40 \mathrm{~cm}-50 \mathrm{~cm}$ soil layer, no significant differences in HA content were evident between R1 and R10 as well as between R20 and R30; however, that of R55 was significantly higher than those of other farming durations. A decrease in HA content with increasing depth was evident for soils of all farming durations. The soil HA contents between the $0 \mathrm{~cm}-10 \mathrm{~cm}$ and $40 \mathrm{~cm}-50 \mathrm{~cm}$ soil layers were significantly different $(P<0.05)$. The $0 \mathrm{~cm}-10 \mathrm{~cm}$ soil HA contents for R1, R10, R20, R30 and R55 
soils were higher than their respective $40 \mathrm{~cm}-50 \mathrm{~cm}$ layers by $1.07 \mathrm{~g} \cdot \mathrm{kg}^{-1}, 1.64 \mathrm{~g} \cdot \mathrm{kg}^{-1}$, $1.4 \mathrm{~g} \cdot \mathrm{kg}^{-1}, 1.4 \mathrm{~g} \cdot \mathrm{kg}^{-1}$ and $1.23 \mathrm{~g} \cdot \mathrm{kg}^{-1}$, respectively. These results indicates a buildup of soil HA with increasing farming duration. In addition, HA content decreased with increasing depth, suggesting that the surface layer gains the most HA with increasing farming duration.

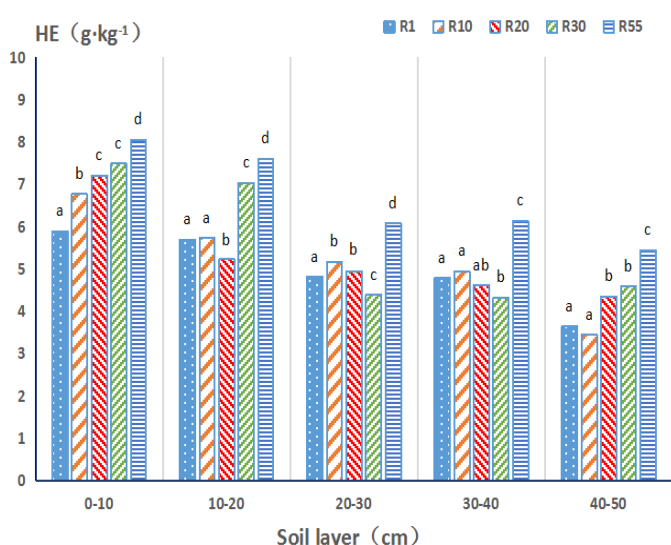

Figure 4. Vertical distribution of humus carbon in saline-alkaline soil over different farming durations Note: lowercase letters indicate a significant difference at $P<0.05$

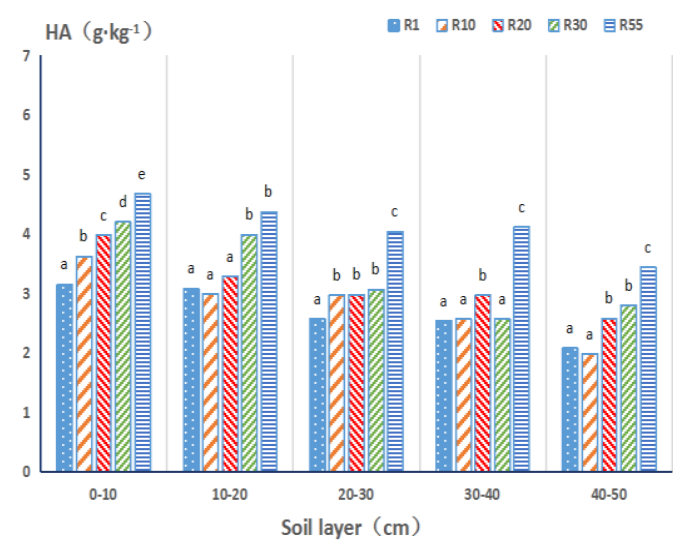

Figure 5. Vertical distribution of humic acid in saline-alkaline soil over different farming durations

\section{Variations in Fulvic Acid Content}

Fulvic acid (FA) is low in molecular weight, with a brown or black surface appearance and is soluble in acid, alkali and ethanol solutions and water. FA is beneficial to soils in that it assists in the adsorption of heavy metals and in releasing nutrients (Sacdej and Żołnowski, 2015; Borowska et al., 2015). Figure 6 illustrates that the $0 \mathrm{~cm}-10 \mathrm{~cm}$ R1 soil layer FA content was dramatically higher than those of other farming durations $(P<0.05)$ and those of R10, R20, R30 and R55 soils remained relatively stable across all farming durations at $3.15 \mathrm{~g} \cdot \mathrm{kg}^{-1}, 3.23 \mathrm{~g} \cdot \mathrm{kg}^{-1}, 3.29 \mathrm{~g} \cdot \mathrm{kg}^{-1}$ and $3.39 \mathrm{~g} \cdot \mathrm{kg}^{-1}$, respectively. For the 10 $\mathrm{cm}-20 \mathrm{~cm}$ soil layer, no significant difference in FA was evident between Rl and R30 as well as between R30 and R55, whereas that of R30 (3.05 g kg-1) was significantly lower than those of other farming durations. For the $20 \mathrm{~cm}-30 \mathrm{~cm}$ soil layer, no significant differences were evident between R1 and R10 as well as between R20 and R55, whereas that of R20 $\left(1.98 \mathrm{~g} \cdot \mathrm{kg}^{-1}\right)$ was notably lower than those of other farming durations. For the $30 \mathrm{~cm}-50 \mathrm{~cm}$ soil layer, no significant difference was evident between R1 and R10 as well as between R20 and R30. No consistent pattern was evident in soil FA content for different farming durations and between soil layers. The soil FA content appeared to accumulate with increasing farming duration in the $0 \mathrm{~cm}-10 \mathrm{~cm}$ and $40 \mathrm{~cm}-50 \mathrm{~cm}$ soil layers, whereas it decreased before increasing in the $10 \mathrm{~cm}-40 \mathrm{~cm}$ soil layer, and was relatively low in R20 and R30 soils.

\section{Variations of Humin Content}

Humin (HM) is a humus component which combines most closely with soil minerals, and cannot be extracted by any acid, alkali or organic solvents. Therefore, as 
an inert humus component, it is the most resistant to decomposition and can exist in soil for over a thousand years (Newcomb, 2015). In recent years, studies have shown that $\mathrm{HM}$ is composed of carbonized microbial protoplasmic and plant residues, and that due to its ubiquitous presence in the natural environment, can be used as an electron mediator to promote bioremediation of organic pollutants. As a result, there is a growing interest in this substance (Kramer et al., 2004). Figure 7 illustrates that the $0 \mathrm{~cm}-10 \mathrm{~cm}$ HM soil content tended to increase first and then decrease with increasing farming duration. In addition, R1 and R30 soils had the lowest and highest HM contents at $6.89 \mathrm{~g} \cdot \mathrm{kg}^{-1}$ and $8.06 \mathrm{~g} \cdot \mathrm{kg}^{-1}$, respectively, with no significant difference evident between R1 and R10 as well as between R30 and R55. HM in the $10 \mathrm{~cm}-20 \mathrm{~cm}$ soil layer appeared to increase with increasing farming duration. However, HM contents for this layer in the R1, R10 and R20 soils remained stable at between $6.08 \mathrm{~g} \cdot \mathrm{kg}^{-1}$ $6.64 \mathrm{~g} \cdot \mathrm{kg}^{-1}$ and between $7.73 \mathrm{~g} \cdot \mathrm{kg}^{-1}-7.81 \mathrm{~g} \cdot \mathrm{kg}^{-1}$ for R30 and R55 soils. The HM content of the $20 \mathrm{~cm}-50 \mathrm{~cm}$ soil layer increased, then decreased and then increased again with increasing farming duration, and was highest in the R10 and R55 soils with no significant difference between R1 and R20 soils. R55 presented the highest HM content, with values of $6.57 \mathrm{~g} \cdot \mathrm{kg}^{-1}, 6.82 \mathrm{~g} \cdot \mathrm{kg}^{-1}$ and $5.64 \mathrm{~g} \cdot \mathrm{kg}^{-1}$ for the $20 \mathrm{~cm}-30 \mathrm{~cm}$, $30 \mathrm{~cm}-40 \mathrm{~cm}$ and $40-50 \mathrm{~cm}$ soil layers, respectively. All soils showed decreasing HM content with increasing soil depth, indicating that that uppermost soil layer is subject to heavier HM accumulation.

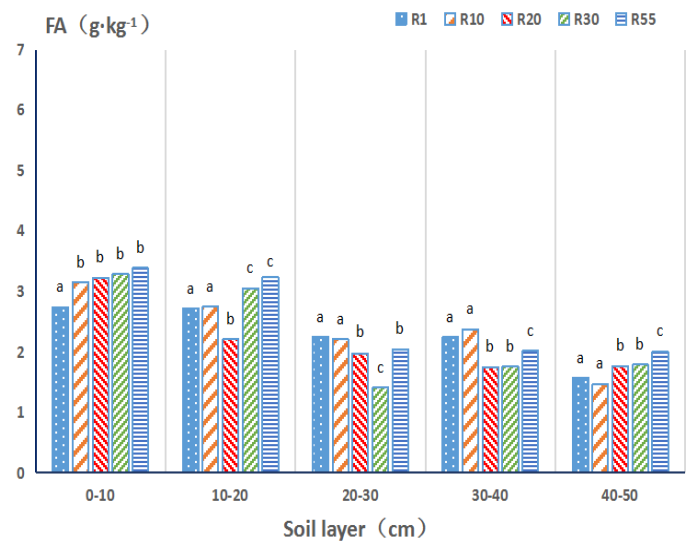

Figure 6. Vertical distribution of fulvic acid in saline-alkaline soil over different farming durations

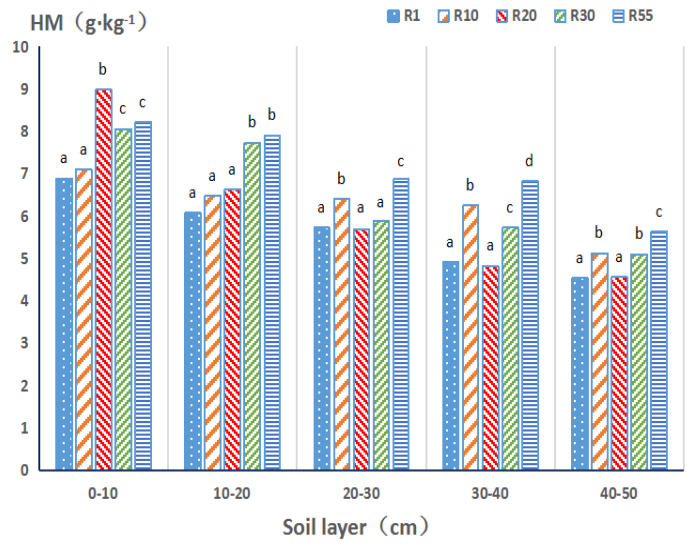

Figure 7. Vertical distribution of humin in saline-alkaline soil over different farming durations Note: lowercase letters indicate a significant difference at $P<0.05$

\section{Analysis of the Variations in Humus Components in Saline-alkali Paddy Soil}

Variations in the composition and content of soil humus reflect the mechanisms behind soil formation and evolution (Liu et al., 2019). Table 2 shows the proportions of humic components (HE, HA, FA and HM) in organic carbon. It can be seen that HM accounted for the largest proportion at $>50 \%$ of soil organic carbon. Generally, the proportions of soil components in soil organic carbon was in the order of $\mathrm{HM}>\mathrm{HE}>\mathrm{HA}>\mathrm{FA}$, indicating that stable HM made up the majority of soil humus. In the $0 \mathrm{~cm}-10 \mathrm{~cm}, 10 \mathrm{~cm}-20 \mathrm{~cm}, 20 \mathrm{~cm}-30 \mathrm{~cm}$ and $30 \mathrm{~cm}-50 \mathrm{~cm}$ soil layers, the value of 
$[(\mathrm{HM}) /(\mathrm{SOC})] \%$ and $[(\mathrm{HE}) /(\mathrm{SOC})] \%$ decreased and increased with increasing farming duration, respectively. Table 3 shows a consistently significant positive correlation between soil HE, HA, FA, HM and SOC across all farming durations. This indicates a close internal correlation between soil humus components. A strong correlation between soil humus components and soil organic carbon was also evident, indicating that the stability of soil organic carbon was related to humus content.

Table 2. Soil humus composition as a proportion of organic carbon

\begin{tabular}{|c|c|c|c|c|c|c|}
\hline \multirow{2}{*}{$\begin{array}{l}\text { Sample } \\
\text { number }\end{array}$} & \multirow{2}{*}{$\begin{array}{l}\text { Proportion of } \\
\text { organic carbon } \\
\text { in soil } \\
\end{array}$} & \multicolumn{5}{|c|}{ Soil layer/(cm) } \\
\hline & & 0-10 & 10-20 & $20-30$ & 30-40 & $40-50$ \\
\hline \multirow{4}{*}{$\mathrm{R} 1$} & {$[(\mathrm{HM}) /(\mathrm{SOC})] \%$} & 53.91 & 51.61 & 54.31 & 50.67 & 55.43 \\
\hline & {$[(\mathrm{HE}) /(\mathrm{SOC})] \%$} & 46.09 & 48.39 & 45.69 & 49.33 & 44.57 \\
\hline & {$[(\mathrm{HA}) /(\mathrm{SOC})] \%$} & 24.65 & 25.30 & 24.36 & 26.16 & 25.40 \\
\hline & {$[(\mathrm{FA}) /(\mathrm{SOC})] \%$} & 21.44 & 23.09 & 21.33 & 23.17 & 19.17 \\
\hline \multirow{4}{*}{ R10 } & {$[(\mathrm{HM}) /(\mathrm{SOC})] \%$} & 51.19 & 52.21 & 55.31 & 54.02 & 59.74 \\
\hline & {$[(\mathrm{HE}) /(\mathrm{SOC})] \%$} & 48.81 & 47.79 & 44.69 & 45.98 & 40.26 \\
\hline & {$[(\mathrm{HA}) /(\mathrm{SOC})] \%$} & 26.10 & 25.29 & 25.63 & 24.73 & 23.10 \\
\hline & {$[(\mathrm{FA}) /(\mathrm{SOC})] \%$} & 22.71 & 22.50 & 19.07 & 21.25 & 17.15 \\
\hline \multirow{4}{*}{$\mathrm{R} 20$} & {$[(\mathrm{HM}) /(\mathrm{SOC})] \%$} & 55.47 & 55.94 & 53.52 & 50.05 & 51.18 \\
\hline & {$[(\mathrm{HE}) /(\mathrm{SOC})] \%$} & 44.53 & 44.06 & 46.48 & 49.95 & 48.82 \\
\hline & {$[(\mathrm{HA}) /(\mathrm{SOC})] \%$} & 24.58 & 25.44 & 27.89 & 31.43 & 28.96 \\
\hline & {$[(\mathrm{FA}) /(\mathrm{SOC})] \%$} & 19.95 & 18.62 & 18.59 & 18.52 & 19.87 \\
\hline \multirow{4}{*}{ R30 } & {$[(\mathrm{HM}) /(\mathrm{SOC})] \%$} & 51.83 & 52.34 & 57.25 & 51.99 & 52.63 \\
\hline & {$[(\mathrm{HE}) /(\mathrm{SOC})] \%$} & 48.17 & 47.66 & 42.75 & 48.01 & 47.37 \\
\hline & {$[(\mathrm{HA}) /(\mathrm{SOC})] \%$} & 27.01 & 27.01 & 29.02 & 30.52 & 28.90 \\
\hline & {$[(\mathrm{FA}) /(\mathrm{SOC})] \%$} & 21.16 & 20.65 & 13.73 & 17.50 & 18.47 \\
\hline \multirow{4}{*}{ R55 } & {$[(\mathrm{HM}) /(\mathrm{SOC})] \%$} & 50.49 & 50.32 & 50.69 & 52.62 & 50.86 \\
\hline & {$[(\mathrm{HE}) /(\mathrm{SOC})] \%$} & 49.51 & 49.68 & 49.31 & 47.38 & 49.14 \\
\hline & {$[(\mathrm{HA}) /(\mathrm{SOC})] \%$} & 28.69 & 28.80 & 33.49 & 31.79 & 31.02 \\
\hline & {$[(\mathrm{FA}) /(\mathrm{SOC})] \%$} & 20.82 & 20.88 & 15.82 & 15.59 & 18.12 \\
\hline
\end{tabular}

Abbreviations: humus carbon (HE), Humic acid (HA), fulvic acid (FA), Humin (HM), soil organic carbon (SOC)

\section{Variations in Humus Composition of Saline-alkali Paddy Soil}

The degree of soil humification and quality of humus are generally measured by values of HA/FA and PQ (the ratio of HA to $\mathrm{HE}$ ), with higher values indicating better soil quality (Shu et al., 2015). The results of Figure 8 and Figure 9 showed that the HA/FA and PQ values of soil humus in different tillage years had the same trend, which was R55 $>\mathrm{R} 30>\mathrm{R} 20>\mathrm{R} 10>\mathrm{R} 1$. However, the changes of HA/FA and PQ of humus in different soil layers were not completely consistent, and the changes of HA/FA and PQ of R1 and R10 showed a "W"-type trend with the depth of soil layers, the values of HA/FA and PQ of R20, R30 and R55 in the soil layers of 10-20 cm and 30-40 cm, respectively showed a trend of increasing first and then decreasing with the depth of soil layers, and the peak value was $20-30 \mathrm{~cm}$. The HA/FA and PQ of Soil in different tillage years were higher than 1 and 0.5, respectively, because the humus in soil was renewed and activated every year. The values of HA/FA and PQ in $20-30 \mathrm{~cm}$ soil layer increased the most, and the values of $\mathrm{HA} / \mathrm{FA}$ and PQ in R55 were $85.96 \%$ and $28.3 \%$ higher than those in R1 soil 
layer, which indicated that the tillage years could significantly increase the values of HA/FA and PQ, the proportion of humic acid increased gradually, and the soil humus quality improved gradually. In addition, we also know that soil layer and reclamation years are the two factors that control the contents of HE, HA and FA (Table 4).

Table 3. Analysis of the correlation between soil humus composition and soil organic carbon

\begin{tabular}{|c|c|c|c|c|c|c|}
\hline Sample number & Index & SOC & HM & HE & HA & FA \\
\hline R1 & $\begin{array}{c}\text { SOC } \\
\text { HM } \\
\text { HE } \\
\text { HA } \\
\text { FA }\end{array}$ & 1 & $\begin{array}{c}.979 * * \\
1\end{array}$ & $\begin{array}{c}.977 * * \\
.913 * \\
1\end{array}$ & $\begin{array}{c}.988 * * \\
.939 * \\
.995 * * \\
1\end{array}$ & $\begin{array}{c}.959 * \\
.882 * \\
.996 * * \\
.982 * * \\
1\end{array}$ \\
\hline R10 & $\begin{array}{c}\text { SOC } \\
\text { HM } \\
\text { HE } \\
\text { HA } \\
\text { FA }\end{array}$ & 1 & $\begin{array}{c}.990^{* *} \\
1\end{array}$ & $\begin{array}{c}.997 * * \\
.976^{* *} \\
1\end{array}$ & $\begin{array}{c}.999^{* *} \\
.996^{* *} \\
.991^{* *} \\
1\end{array}$ & $\begin{array}{c}.978^{* *} \\
.940^{*} \\
.992^{* *} \\
.966^{* *} \\
1\end{array}$ \\
\hline $\mathrm{R} 20$ & $\begin{array}{c}\text { SOC } \\
\text { HM } \\
\text { HE } \\
\text { HA } \\
\text { FA }\end{array}$ & 1 & $\begin{array}{c}.996^{* *} \\
1\end{array}$ & $\begin{array}{c}.990 * * \\
.974 * * \\
1\end{array}$ & $\begin{array}{c}.963 * * \\
.938^{*} \\
.987 * * \\
1\end{array}$ & $\begin{array}{c}.993 * * \\
.984 * * \\
.990 * * \\
.955^{*} \\
1\end{array}$ \\
\hline R30 & $\begin{array}{c}\text { SOC } \\
\text { HM } \\
\text { HE } \\
\text { HA } \\
\text { FA }\end{array}$ & 1 & $\begin{array}{c}.988^{* *} \\
1\end{array}$ & $\begin{array}{c}.989 * * \\
.955^{*} \\
1\end{array}$ & $\begin{array}{c}.994 * * \\
.977^{* *} \\
.989^{* *} \\
1\end{array}$ & $\begin{array}{c}.971 * * \\
.925^{*} \\
.994^{* *} \\
.966^{* *} \\
1 \\
\end{array}$ \\
\hline R55 & $\begin{array}{c}\text { SOC } \\
\text { HM } \\
\text { HE } \\
\text { HA } \\
\text { FA }\end{array}$ & 1 & $\begin{array}{c}.994^{* *} \\
1\end{array}$ & $\begin{array}{c}.995^{* *} \\
.978^{* *} \\
1\end{array}$ & $\begin{array}{c}.910^{*} \\
.916^{*} \\
.894^{*} \\
1\end{array}$ & $\begin{array}{c}.936^{*} \\
.905^{*} \\
.954^{*} \\
0.719 \\
1\end{array}$ \\
\hline
\end{tabular}

Note: Correlation coefficients labeled by $*$ and $* *$ indicate significant difference at $\mathrm{P}=0.05$ and $\mathrm{P}=0.01$, respectively. Abbreviations: humus carbon (HE), Humic acid (HA), fulvic acid (FA), Humin (HM), soil organic carbon (SOC)

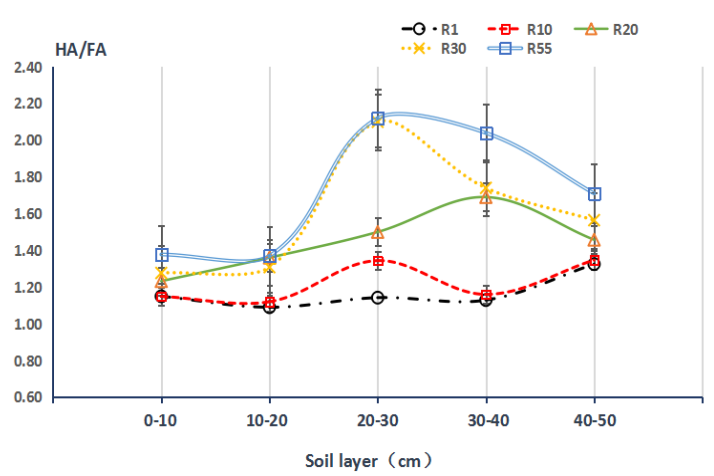

Figure 8. Trends in the relative proportions of saline-alkaline soil $\left(C_{H A} / C_{F A}\right)$ over different farming durations

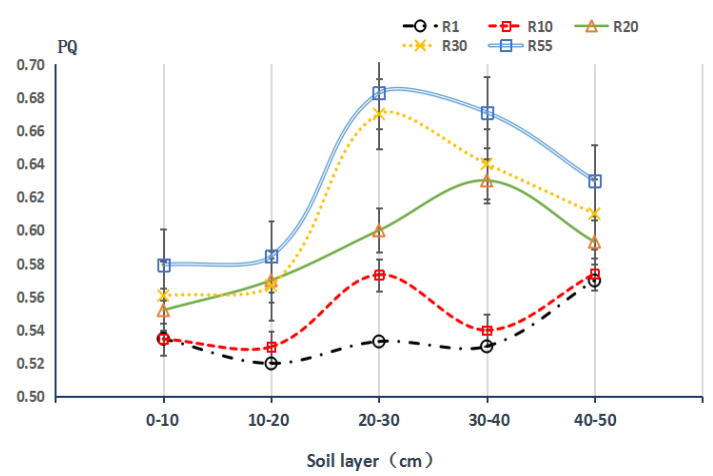

Figure 9. Trends in $P Q$ values of salinealkaline soil over different farming durations

Note: The error line in figure shows the positive and negative deviation of the value 
Table 4. Multifactor Variance Analysis of Soil HE, HA and FA in Saline-alkali Rice Paddy Soil during Soil Layer, Reclamation years

\begin{tabular}{c|c|c|c|c|c|c}
\hline Index & Source of variation & $\begin{array}{c}\text { Sum of } \\
\text { squares }\end{array}$ & $\begin{array}{c}\text { Degree of } \\
\text { freedom }\end{array}$ & Mean square & F & P \\
\hline \multirow{3}{*}{ HE } & Soil layer & 608.312 & 4 & 152.078 & 1221.48 & $*$ \\
& Reclamation years & 1755.474 & 4 & 438.868 & 3524.965 & $*$ \\
& Soil layer * Reclamation years & 62.121 & 16 & 3.883 & 31.184 & $*$ \\
& Soil layer & 157.722 & 4 & 39.431 & 1163.278 & $*$ \\
& Reclamation years & 448.556 & 4 & 112.139 & 3308.319 & $*$ \\
& Soil layer * Reclamation years & 14.206 & 16 & 0.888 & 26.194 & $*$ \\
& Soil layer & 126.172 & 4 & 31.543 & 1298.59 & $*$ \\
FA & Reclamation years & 318.766 & 4 & 79.692 & 3280.811 & $*$ \\
& Soil layer * Reclamation years & 12.144 & 16 & 0.759 & 31.246 & $*$ \\
\hline
\end{tabular}

Note: $\mathrm{P}<0.001$

\section{Discussion}

Humus generally undergoes synthesis and decomposition during its formation. Soil humus composition is partly derived from the decomposition of plant residues and partly from the synthesis of microorganisms $(\mathrm{Cu}, 2015)$; therefore, its content is related to the process of soil mineralization and humification. In the present study, the proportions of soil humus components (HA, FA and HM) gradually increased with increasing farming duration, consistent with the results of Clark et al. (1998), Pimente et al. (2005) and Melerol et al. (2006), who showed consistent increases in soil organic carbon and humus carbon with increasing soil cultivation time. This can be explained by considering that soil microorganisms directly participate in the degradation and humification of organic residues; farming provides more suitable temperature and humidity conditions for microorganisms, thereby increasing microbial activity in soil. In this way, the decomposition of soil organic carbon is increased along with soil mineralization and humification, resulting in a rise in the soil organic carbon and humus contents (Yu et al., 2004; Watanabe et al., 2007; Wissing et al., 2013).

The variances of soil carbon content and humus components across different farming durations and soil layers has also resulted in some regular variations in the proportion of organic carbon in each component. HM was found to make up the largest proportion in soil, accounting for approximately half of organic carbon. In general, the rank proportion of each component in soil was HM > HE > HA > FA, with a significant correlation between soil humus components and organic carbon evident. This indicates that the majority of humus exists as stable HM, and that saline-alkaline paddy soils have certain potentials for carbon sequestration.

The relative variations in soil humus components can also be analyzed by comparing the values of specific indicators, namely HA/FA or PQ. The total amount of humus and the degree of soil humification increased with increasing soil maturity, with HA/FA values of $1.4,0.5$ and $0.2-0.3$ for highly mature, moderately mature and relatively immature paddy soils, respectively (Liu et al., 2017). In the present study, increasing farming duration resulted in an improvement in HA content across all soil layers. Moreover, both HA, HA/FA and PQ values increased with increased duration of rice farming. This indicates that an increase in the amount of soil HA resulted in an increase 
in soil humification, thereby also improving soil maturity, humus quality and fertility (Liu et al., 2018). The variations in and regeneration of soil humus can not only be used to evaluate soil quality and vegetation restoration, but also bears vital significance for soil carbon sequestration. Paustian pointed out that the chemical combination of soil humus and soil minerals serves as an important mechanism for the stabilization of organic carbon and prevention of microbial degradation (Paustian et al., 1992). Therefore, further studies on the molecular structure of humus and the mechanism of regulation of molecular in-situ polymerization for saline-alkali paddy soils would play an important role in limiting soil microbial mineralization and improving soil organic carbon sequestration.

\section{Conclusion}

(1) Variations in soil humus were found across different farming durations and soil layers. Soil humic acid content increased significantly with increasing farming duration. In general, the soil humus components were found to decrease in value with increasing soil depth. Farming maintained soil fulvic acid content at a relatively stable level across all farming durations. Humin made up the largest proportion of humus in saline-alkaline paddy soil and increased remarkably with increased farming duration, with the largest accumulation in the top soil. (2) Soil humus components (humic acid, fulvic acid and humin) were significantly correlated with organic carbon content, and the regeneration and activation of soil humus exerted direct impacts on the variations of the soil organic carbon pool. (3) Farming duration significantly increased the values of HA/FA and PQ of saline-alkali paddy soils with the largest increase shown in the $20-30 \mathrm{~cm}$ soil layer.

As a stable carbon component in soil, soil humus carbon increased with the extension of cultivation years. The content of soil humus carbon after cultivation was significantly higher than that of uncultivated saline-alkali wasteland, the results showed that salinealkali soil was improved and reclaimed as a back-up soil of farmland, and it was also beneficial to improve the function of soil carbon sink. This suggests that we should make better and reasonable use of the reserve land resources, increase production, and at the same time, improve the climate change also has a certain role in promoting.

Funding. This research was funded by National Natural Science Foundation of China (No.51179073, 41471152) and Changchun University Scientific Research and cultivation Fund (2019JBC27L40).

\section{REFERENCES}

[1] Andreetta, A., Ciampalini, R., Moretti, P., Vingiani, S., Poggio, G., Matteucci, G., Tescari, F., Carnicelli, S. (2011): Forest humus forms as potential indicators of soil carbon storage in Mediterranean environments. - Biol. Fertil. Soils 47: 31-40.

[2] Borowska, K., Koper, J., Kozik, K., Rutkowska, A. (2014): Effect of slurry fertilization on the selenium content and catalase activity in lessive soil. - Journal of elementology 19(3).

[3] Brady, N. C. (1974): The Nature and Properties of Soils(8th ed). - MacMillan Publishing Co, New York.

[4] Brady, N. C., Weil, R. R. (2000): Elements of the nature and properties of soils. Pearson Education, USA. 
[5] Bunting, B. T., Lundberg, J. (1987): The humus profile - concept, class and reality. Geoderma 40(1-2): 17-36.

[6] Cha, T. G. (2017): Physical and chemical analysis of soil. - China Forestry Press: Beijing, pp. 177-189.

[7] Chu, H., Zong, L. G., Wang, Z. Y., Xie, S. H., Yang, N., Luo, M. (2013): Dynamic changes in humus composition in vegetable soils different in cultivation Mode. - Acta Pedologica Sinica 50(5): 931-939.

[8] Clark, M. S., Ferris, H., Klonsky, K., Lanini, W. T., Bruggen, A. H. C. V., Zalom, F. G. (1998): Agronomic, economic, and environmental comparison of pest management in conventional and alternative tomato and corn systems in northern california. Agriculture Ecosystems and Environment 68(1-2): 51-71.

[9] $\mathrm{Cu}$, J. T. (2015): Studies on the role of microorganism in the formation and transformation of humus. - Jilin Agricultural University: Jilin.

[10] Daryanti, N. Y., Zulaikah, S., Mufti, N., Haryati, D. S. (2019): Characteristics of magnetic susceptibility and geochemistry of paddy soils in malang city, east java. - IOP Conference Series Earth and Environmental Science 311: 012-032.

[11] Ding, C. X., Yong, Q., Dong, Z. Y., Ruobo, W. (2013): Effects of different land use modes on physical and chemical properties of saline-alkali soil in Yellow River Delta. Science of Soil and Water Conservation 11(2): 84-89.

[12] Dong, S.-S., Dou, S. (2017): Effect of different ways of corn stover application to soil on composition and structural characteristics of organic carbon in black soil. - Journal of Agro-Environment Science 2017-02.

[13] Dong, S.-S., Dou, S., Shao, M. J. (2017): Effect of corn stover deep incorporation with different years on composition of soil humus and structural characteristics of humic acid in black soil. - Journal of Soil Science 054(001): 150-159.

[14] Gong, W., Yan, X. Y., Wang, J. Y., Hu, T. X., Gong, Y. B. (2009): Effects of long-term fertilization on soil humus carbon and nitrogen fractions in a wheat-maize cropping system. - Plant Nutrition and Fertilizer Science 15(6): 1245-1252.

[15] Jonczak, J. (2014): Effect of land use on the carbon and nitrogen forms in humic horizons of stagnic luvisols. - Journal of elementology 19(4): 1037-1048.

[16] Kramer, R. W., Kujawinski, E. B., Hatcher, P. G. (2004): Identification of black carbon derived structures in a volcanic ash soil humic acid by fourier transform ion cyclotron resonance mass spectrometry. - Environmental Science \& Technology 38(12): 3387-3395.

[17] Li, L. Q., Zhang, X. H., Wang, P. (2016): Microbial activity promoted with organic carbon accumulation in macroaggregates of paddy soils under long-term rice cultivation. Biogeosciences 13: 6565-6586.

[18] Liu, X. J., Hu, Y. F., Shu, X. Y., Xu, H. Y., He, J. F., Wang, Q. (2017): Varying characteristics of organic carbon and humus carbon under or outside the branchy tamarisk canopy in sand land in northwest sichuan. - Agricultural Research In The Arid Areas 35(4): 15-21.

[19] Liu, P., Zhou, W. J., Tan, J., Cao, S. (2018): Research progress on structural characteristics of organic carbon and humus in paddy soil. - Southern agriculture 12(33): 183-185.

[20] Liu, Q., Tang, J., Wang, J. J., Qu, Y. K. (2018): Spatial distribution characteristics of soil organic carbon and active components in saline-alkali paddy fields in Western Jilin. Journal of Northeast Agricultural University 49(09): 47-56.

[21] Liu, P., Zhou, W., Cui, H., Tan, J., Cao, S. (2019): Structural characteristics of humic substances in buried ancient paddy soils as revealed by ${ }^{13} \mathrm{c} \mathrm{nmr}$ spectroscopy. Environmental Geochemistry and Health 41: 2459-72.

[22] Melero, S., Porras, J. C. R., Herencia, J. F., Madejon, E. (2006): Chemical and biochemical properties in a silty loam soil under conventional and organic management. Soil \& Tillage Research 90(1-2): 162-170.

[23] Newcomb, C. J. (2015): Humic matter in soil and the environment, principles and controversies. - Soil Science Society of America Journal 79(5): 1520. 
[24] Paustian, K., Parton, W. J., Persson, J. (1992): Modeling soil organic matter in organicamended and nitrogen-fertilized long-term plots. - Soil ence Society of America Journal 56: 476-88.

[25] Pimentel, D., Hepperly, P., Hanson, J., Douds, D., Seidel, R. (2005): Environmental, energetic, and economic comparisons of organic and conventional farming systems. Bioscience Science 55(7): 573-582.

[26] Sądej, W., Żołnowski, A. C. (2015): Effects of different long-term fertilization systems on the content and fractional composition of humic substances in lessive soil. -29 Congress of the Polish Society of Soil Science-soil Resources \& Sustainable Development.

[27] Shao, X. W., Ran, C., Jin, F., Guo, L. Y., Geng, Y. Q. (2018): Advances and Prospects in Research of Rice Cultivation Technology in Saline-sodic Soil of Songnen Plain. - Journal of Jilin Agricultural University 40(04): 5-8.

[28] Shu, Z., Sen, D., Chen, L. Z. (2015): Effect of deep application of straw on composition of humic acid in soil aggregates. - Acta Pedologica Sinica 52(4): 747-758.

[29] Six, J., Bossuyt, H., Degryze, S. (2004): A history of research on the link between (micro)aggregates, soil biota, and soil organic matter dynamics. - Soil \& Tillage Research 79(1): 7-31.

[30] Tang, J., Zhang, N., Li, Z. Y. (2011): Vertical Distribution of Soil Organic Carbon and Carbon Density Under Different Land Use Types in Western Jilin Province. - Journal of Jilin University (Earth Science Edition) 41(4): 1151-1156.

[31] Tang, J., Yun, L., Na, L., Li, Z., Hao, Z. (2012): Soil moisture content and nitrogen impacts on soil organic carbon of saline-alkali paddy field under the effect of freezethaw. - Ecology and Environmental Sciences 21(4): 620-623.

[32] Vos, B., Cools, N., Ilvesniemi, H., Vesterdal, L., Vanguelova, E., Carnicelli, S. (2015): Benchmark values for forest soil carbon stocks in Europe: results from a large scale forest soil survey. - Geoderma 251-152: 33-46.

[33] Wang, R., Yu, G., He, N. (2015): Latitudinal variation of leaf stomatal traits from species to community level in forests: Linkagewith ecosystem productivity. - Scientific Reports 5(5): 14454.

[34] Watanabe, T., Kimura, M., Asakawa, S. (2007): Dynamics of methanogenic archaeal communities based on rrna analysis and their relation to methanogenic activity in japanese paddy field soils. - Soil Biology \& Biochemistry 39(11): 2877-2887.

[35] Wiao, X. Q., Chen, Y. W., Sun, H. (2020): Stabilization of Soil Organic Carbon in Alpine Treeline Ecotone along Altitudinal Gradient in the West of Sichuan Province. - Journal of Northwest Forestry University 35(1): 1-7, 36.

[36] Wissing, L., Kölbl, A., Hausler, W., Schad, P., Cao, Z. H., Kögel-Knabner, I. (2013): Management-induced organic carbon accumulation in paddy soils: the role of organomineral associations. - Soil \& Tillage Research 126: 60-71.

[37] Yu, J. B., Liu, J. S., Wang, J. D., Liu, S. X., Wang, G. P. (2004): Organic carbon variation law of black soil during different tillage period. - Journal of Soil \& Water Conservation 18(1): 27-30.

[38] Zhang, J. J., Dou, S. (2004): Studies on fractionation of soil humus. - Chinese journal of soil science 35(6): 706-709.

[39] Zhang, M., Chen, C., Liu, G. M., Yang, J. S., Yu, S. P. (2014): Suitable utilization of fertilizer and soil modifier to ameliorate physicochemical characteristics of saline-alkali soil and increase crop yields. - Transactions of the Chinese Society of Agricultural Engineering 10: 91-98.

[40] Zheng, Y. J., Zhang, J. B., Tan, J. (2019): Chemical Composition and Structure of Humus Relative to Sources. - Acta Pedologica Sinica 56(2): 386-397.

[41] Zhu, R. H., Zheng, Z. C., Li, T., Liu, H. (2018): Effect of tea plantation age on humus fractions in soil water-stable aggregates. - Research of Environmental Sciences 31(6): 1096-1104. 